\title{
Research on the Auspicious Patterns of Ming and Qing Dynasties Ceramics in Jingdezhen
}

\author{
Ying Zhang and Jinquan Lu \\ (Jingdezhen Ceramic University, Jingdezhen, Jiangxi 333403)
}

\begin{abstract}
A drama plays in the image, never tired of seeing; good words come from mouth, to meet people's desire." Auspicious art has been active in the art of this family, swimming in the elegant and vulgar, penetrating into life. Whether in the aspects of aesthetic and decoration, or in the psychological and spiritual, it is loved by public due to its unique form and content. Ming and Qing dynasties are the golden age of development of Jingdezhen ceramic, blue and white, bucket color, pink, pastels, enamel contest each other, although all of them have different kinds of color, but its contents are based on auspicious patterns. This paper will start from the origin of auspicious and auspicious patterns, to explore the application of auspicious patterns in ceramic decoration in Ming and Qing Dynasties and humanities behind it.
\end{abstract}

Keywords: Auspicious; Auspicious patterns; Jingdezhen Ming and Qing ceramics; Ceramic decoration

\section{景德镇明清陶瓷吉祥图案微探}

\author{
张颖，吕金泉
}

( 景德镇陶瓷大学, 江西 景德镇333403)

摘要: “画中要有戏, 百看才不淢; 出口要吉利, 才合人心意。”吉祥艺术一直活跃在艺术这个大家庭中, 游于雅俗之间, 渗透生活之中。不论在审美和装饰方面, 还是在心理和精神上, 它以其独有的形式和内容, 为大众所喜爱。明清两朝是景德 镇陶瓷发展的黄金时期, 青花、斗彩、古彩、粉彩、珐琅彩争奇斗艳, 尽管各式工艺色泽不同, 但其内容都是以吉祥图案为 主。本文将从吉祥和吉祥图案的渊源出发, 探讨明清时期吉祥图案在陶瓷装饰上的运用和其背后所蕴含的人文内涵。

关键词: 吉祥; 吉祥图案; 景德镇明清陶瓷; 陶瓷装饰

中图分类号: J021 文摘标识码: A

引言

原始先民崇拜自然, 为了自身的护卫和宗族的繁衍想象出守护神, 图腾的出现即源于此。在我国古代 神话中, 常有鱼、鸟、蛙的故事, 《山海经》中有载: “蛇乃化为鱼” 蛇、鱼于人又有密切的 联系, 后世多有人首蛇身、人首鱼身的形象, 可能都与原始图腾有关。早期鸟的形象逐渐演变为代表太阳 的金鸟, 蛙的形象逐渐演变为代表月亮的蟾蜍, 成为吉祥纹样的重要内涵之一。良渚文化玉器上的羽冠神 像和大汶口陶器上的太阳图像, 是古代社会行太阳崇拜的反映。早期的太阳崇拜, 日后逐渐融进吉祥纹样 中去, 成为指日高升、一品当朝的滥解。

\section{1 吉祥文化}

“吉祥”一词可以解释为吉庆祥和。《说文解字》说: “吉, 善也。” “祥, 福也, 一云善。”《中庸》: 国家将兴, 必有祯祥, 吉祥也; 国之将亡, 必有妖䔣, 凶祥也。吉者, 福善之事; 祥者, 佳庆之征。可见 “吉”、“祥” 二字皆有美好之意, 直解为吉利美好的预兆。故 “吉祥” 二字, 自古以来就反映了人们希望 福善瑞庆, 诸事顺意之心愿。所谓 “吉祥止止”, 也表现期待好事连连的愿景。不管是出于现实生活也好, 
人们不但将吉祥挂在口头, 并将其图绘成形, 吉祥图案广泛应用, 小到生活日常, 大到人生仪礼。商和西 周青铜器上的 “象”、“鸟”、“龟” 等, 以及商周古玉的 “县纹”、“龙纹”、“风纹” 等样式, 可以说是我国 古代吉祥图案早期之形式。随着后世的发展, 象征吉祥的图案题材渐广, 应用范围也渐大。

吉祥图案是附在器物上的一种寓意幸福的纹饰, 它用最通俗的语言和最一般的形式, 承载人际之间的 祝福、祈愿、希望。龙风肇始，龙飞凤舞，是中国神话的母题也是吉祥纹样的母题，象征着中国文化的肇 始和繁盛, 孕有蓬勃的生命力。龙凤形象的塑造, 集若干走兽、飞禽的特点而成, 成为中国吉祥图案中最 典型的标本。古人画鸡画羊，可谓真正的“吉祥图”。借用谐音，用鸡羊表示 “吉祥”。

\section{2 瓷上吉祥图案}

陶瓷是我国古代先民智慧的结晶。上至宫廷庙堂，下至百姓人家，随处可见陶瓷的痕迹。在它的发展 过程中一直与人们的生活保持着紧密的联系, 久而久之陶瓷的功能从实用转变成一种表达人们愿望的媒 介。从单色釉刻划花的简明素净，釉下绘青花的清丽悦目到斗彩、粉古彩的富丽斑斓，吉祥纹样都是陶瓷 装饰中一个重要元素, 不仅增加了陶瓷的美感, 丰富了人们的感官体验, 更承载了人们对生活的美好愿望。

陶瓷中常见的吉祥图案可以五大类, 分是动物、植物、人物、事物和文字。动物类可分为神兽、禽兽、 水族、羽族四类，多数与人们的政治、宗教和日常生活密切相关。神兽有龙、风、麒麟、白鹿等，其他还 有虎、豹、狮子、象、羊、猴、兔等, 数量相对较少。羽族类出现较多, 有人们熟知的鹤、喜鹊、绶带鸟、 鹤敦、燕子等。水族类动物仅有龟、鱼等少数几种。

植物类则以牡丹、石榴、灵芝、桃、菊、玉兰花、芙蓉花、杏、松、竹、梅、梧桐、佛手、兰花、万 年青、核桃、柿子、荔枝、麦穗、萱草、葫芦等样式最为常见。

瓷上绘人物多见八仙、福禄寿三星、寿星老人、彭祖、刘海蟾、观音、萧史、琴高、婴儿、文士等; 十八罗汉也有用之者。

事物类有藏传佛教八宝（轮、螺、伞、盖、花、罐、鱼、长），又称八吉祥。道教八宝（火珠、钱、 五色祥云、书册、书卷、灵芝、鼎、元宝、馨、方胜、犀角、芭蕉、珊瑚等), 称为杂宝。还有八仙所持 法器（宝剑、笏板、葫芦、鱼鼓、芭蕉扇、花篮、荷花、笛子), 又称暗八仙。其他还有诸如觘、琴、棋、 果品、书画、鼎、彝、尊配合花卉而成博古图。

有时直接书文字于瓷器上，如 “金玉满堂”、“福寿康宁”、“长命富贵”、“寿”、“家国永安”、“一日无 事深谢天地大吉”、“福”、“福延寿长”、“永保长春”、大悲咒之六字真言等等。

\section{3 明清瓷上吉祥图案}

明清时期，民风炽盛，风俗绘画多见，吉祥图案到处呈现，涉及到绘画及工艺美术各个领域。这时期 的吉祥图画, 以图画、版画、瓷画最为多见。瓷器上运用画笔、刀刻及贴印的技法, 为器面增添纹饰。其 中有意喻富贵、名禄及福寿的图案, 也有与佛教道教及传说有关。吉祥图案的安排与选材, 在各个时期各 有其规则。

\section{1 明代}

明代早期，洪武永乐时期的陶瓷吉祥图案，多见花卉、人物、西瓜、荔枝、葡萄、枇杷等折枝花果。 龙、风题材更是多见于盘、碗、罐、壶上。至明宣德年间, 元代流行的八宝还可见到, 一如元之旧历, 也 装饰于梅瓶的器肩上。宣德、成化时期的作品多见海兽纹, 至万历一朝更为风行。明中期流行的吉祥图案 
有贞戏图, 代表雨龙的燕龙, 莲花托杂宝——银锭、犀角、方胜、红叶、珊瑚等。另外岁寒三友及万年青 也常见。成化窑瓷器以十字金刚杵、五供养为饰。五供养为法螺、桃实、莲花、烛台及冰山。明正德时期, 朱厚照崇信伊斯兰教, 御用瓷以阿拉伯文为饰风气盛行, 文字内容主要是吉祥语、筬言、可兰经, 多有祈 福求祥之意, 有鲜明的时代特征和艺术特色。

明晚期嘉靖隆庆万历三朝吉祥图案更为繁富。自正德以后, 图案的种类愈来愈丰富, 寓意也偏重于祈 福求禄求寿, 还要多子多孙。可见人越来越富足愈希望多重保障, 这种心理反映在器物的装饰图案上, 同 一件器血采用复式的吉祥图案——福禄寿俱全, 还要增添仙人、珍宝、及各色珍奇花木虫草。嘉靖皇帝, 崇信道教, 迷恋长生不老, 这时期瓷器造型和装饰富有浓郁的道教色彩, 盛装仙丹的葫芦为嘉靖时的典型 器物。中国国家博物馆藏的一件 “青花八仙人物纹葫芦瓶”, 就是嘉靖时期的典型器物。葫芦瓶造型新颖, 上圆下方, 取 “天圆地方” 之意。瓶身上部以青花绘云鹤、八卦、如意云头纹, 中部有仰覆莲瓣为饰, 下 部绘八仙人物、祥云纹、天马和寿山福海等纹饰, 上下呼应, 道教意蕴浓厚。万历窑曾烧一件青花人物碗, 碗心绘一蟠龙, 碗底写 “大明万历年制”。外壁分绘四幅人物画。第一段绘一文士抬头而立手指太阳, 一 只蝙蝠迎面飞来。这意味着 “指日高升”、“福在眼前”。第二段则描绘一童子手捧盘, 盘置官服, 意味着 “加官进爵”。第三段, 文士手执笏板, 直指前方, 原来是一只蜘蛛从松树上挂下来。意味着 “喜从天降”。 第四段为一童子手捧礼盒, 盒内端置一只梅花鹿, 意为 “晋秩禄位”。

\section{2 清代}

清代瓷器, 不论官窑或民窑, 皆以寓意和谐音来象征吉祥的图案, 使用得比明代更广泛。常用的吉祥 图案有龙风、牡丹、桃子、石榴、松鹤、喜鹊、白鹿、鹤敦等。这时期吉祥图案, 寓意的方式更为自由, 题材之象征、谐音、往往欲使画中的内容, 凑成四字一句的吉祥语, 有时为了硬凑, 还常取物名之谐音, 以凑成完整的诗句。雍正时期的陶瓷多歌颂昇平的图案, 有 “长治久安” 和 “玉堂富贵” 等。雍正窑 “松 鹤常春” 粉彩茶盅, 白鹤栖在藤萝缠绕的松树上, 松根旁长着灵芝和竹叶。鹤是羽族之长, 有 “一品鸟” 之称, 又是长寿仙离; 松是百木之长, 遇霜雪而不调, 历千年而不殒。故松鹤组合被视为祝颂、祈盼青春 永驻, 健康长寿的象征。

清代为倡导藏传佛教, 在各地广建庙宇, 景德镇御窑厂也生产宗法用器, 有些专为蒙、藏地区所制, 反映了内地与少数民族地区的交流与融合。

乾隆朝, 景德镇御窑厂为迎合皇帝标新立异的追求, 器型屡有新创, 奇巧之物, 层出不穷。此时瓷上 吉祥图案的另一特色是增加了许多新的事物, 或是同一事物, 取意的方向有所不同。如台北故宫博物院藏 的一件粉彩福寿冠架, 架顶镂空的图案为五色祥云和红色双蝠, 四组镂空开光均为 “寿”、两 “氾” 字。 意为 “洪福齐天”、“万福万寿”。以红蝠谐音 “洪福”, 以 “凹” 字谐音 “万” 字。冠架的支柱也以相同的 纹饰装饰之。以这种方式表现无边无尽的 “福寿”, 这是明代所未见的。另有粉彩婴戏图瓶一例, 所绘 “百 子观灯” 图。腹壁整圈留白描绘童子持灯, 赏灯之元宵佳节欢庆场面。一众童子中有头戴纱帽的贵族子弟 三两个, 其余均为髺龄小童, 敲锣打鼓放炮, 持灯前呼后拥。这等场面, 在明代的贞戏图中也是见不到的。

晚晴时期有些新兴的吉祥图案, 如咸丰窑粉彩花鸟方瓶, 绿地描花, 四面有开光。其中一个开光, 绘 着南天竹, 枝上缀满红色小果, 一对红色的绶带鸟栖于枝上, 合成 “天仙拱寿”。有一开光画的是背驮金 红色彩瓷的白象, 锦革披垂, 瓶中绘插桂花枝、兰草和结实累累的石榴。前置一盆万年青, 旁有石头及常 
春花。其意为 “太平有象”, “榴开百子”, “兰桂齐芳”, “万寿长春”。光绪窑粉彩百蝶图, 各色彩蝶, 环 腰一圈寿字和菊花, 其意 “菊寿老薪”, 在明亦不多见。

\section{结语}

造物活动建立了外在的物质世界和人类精神观象在内的生活世界之间彼此呼应的联系。人类精神的丰 富性恰好在造物中寻找到一个宣泄口和栖息地, 这一事实促使我们突破简单的物质性质层面来看待造物活 动, 并同人生存于其中的完整世界之间的联系当中对它加以考察和认识。吉祥文化是我国传统文化的重要 组成部分, 辐射面广, 凡剪纸花样、园林门窗、陶瓷漆器、织锦花布, 无不有各式各样、丰富多彩的吉祥 图案。

明清两朝是我国资本主义萌芽发展时期, 工艺美术也随着社会生产力和商品经济的发展而走向高潮。 明清是景德镇陶瓷发展历史上的集大成时期, “集天下名窑之大成, 汇全国技艺之精华。” 那些绘制着吉祥 图案的陶瓷，不仅仅是具有民族艺术特色的物品，更向我们展示着古代人民对美好幸福如何憧憬。

\section{参考文献:}

[1]张道一.吉祥文化论[M]. 重庆大学出版社. 2011

[2]大乔. 图说中国吉祥物 [M]. 中国社会科学出版社. 2008

[3] 蓝浦. 景德镇陶录 [M]. 黄山书社. 2016

[4]李泽厚. 美的历程 $[\mathrm{M}]$. 生活・读书・新知三联书店. 2009

[5] 李砚祖. 装饰之道 [M]. 中国人民大学出版社. 1993

[6]殷志强. 吉祥图案面面观 [J]. 故宫文物. 1988 (10) : 74-95

[7]王树村. 中国历代图案吉祥管窥 [J]. 中国文化. 1990（1）:41-46

作者简介:

张颖, (1990-), 女, 景德镇陶瓷大学, 博士研究生, 设计学

吕金泉, (1964-), 男, 景德镇陶瓷大学陶瓷美术学院院长, 教授, 博士生导师, 研究方向: 设计学

\section{References:}

[1] Zhang Daoyi. Auspicious culture [M]. Chongqing University Press. 2011

[2] Da Qiao. Figures say Chinese mascot [M]. China Social Science Press. 2008

[3] Lan Pu. Jingdezhen ceramic record [M]. Huangshan Book Society. 2016

[4] Li Zehou. The history of the beauty [M]. Life · Reading · Xinzhi Sanlian Bookstore. 2009

[5] Li Yanzu. Decorative Road [M]. Renmin University of China Press. 1993

[6] Yin Zhijiang. View of Auspicious pattern [J]. National Palace Museum. 1988 (10): 74-95

[7] Wang Shucun. Review of Chinese historical pictorial auspicious [J]. Chinese Culture. 1990 (1): 41-46 